\title{
Synthesis of Multilayered DLC Films with Wear Resistance and Antiseizure Properties
}

\author{
Yucheng $\mathrm{Li}^{1, *}$, Jun Enomoto ${ }^{1} \mathbb{D}$, Yuki Hirata ${ }^{2}$, Hiroki Akasaka ${ }^{1}$ and Naoto Ohtake ${ }^{2} \mathbb{D}$ \\ 1 Department of Mechanical Engineering, Tokyo Institute of Technology, 2-12-1, O-okayama, Meguro-ku, \\ Tokyo 152-8550, Japan; enoenojunjuwar.0111@gmail.com (J.E.); akasaka.h.ac@m.titech.ac.jp (H.A.) \\ 2 Institute of Innovative Research (IIR), Tokyo Institute of Technology, 4259 Nagatsuta, Midori-ku, Yokohama, \\ Kanagawa 226-8503, Japan; hirata.y.ac@m.titech.ac.jp (Y.H.); ohtake.n.aa@m.titech.ac.jp (N.O.) \\ * Correspondence: li.y.bf@m.titech.ac.jp; Tel.: +81-45-924-5099
}

Citation: Li, Y.; Enomoto, J.; Hirata, Y.; Akasaka, H.; Ohtake, N. Synthesis of Multilayered DLC Films with Wear Resistance and Antiseizure Properties. Materials 2021, 14, 2300. https:// doi.org/10.3390/ma14092300

Academic Editors: Andrew Ruys and Naoto Ohtake

Received: 30 March 2021

Accepted: 27 April 2021

Published: 29 April 2021

Publisher's Note: MDPI stays neutral with regard to jurisdictional claims in published maps and institutional affiliations.

Copyright: (c) 2021 by the authors. Licensee MDPI, Basel, Switzerland. This article is an open access article distributed under the terms and conditions of the Creative Commons Attribution (CC BY) license (https:// creativecommons.org/licenses/by/ $4.0 /)$.

\begin{abstract}
Diamond-like carbon (DLC) films have attracted considerable interest for application as protective films in diverse industrial parts. This is attributed to their desirable characteristics, such as high hardness, low coefficient of friction, gas-barrier properties, and corrosion resistance. Antiseizure properties, in addition to wear resistance, are required during the die molding of polymer and polymer-matrix composite parts. Graphite films can be easily peeled because the vertically stacked graphene sheets are bonded via weak van der Waals forces. The present study demonstrates the fabrication of multilayered DLC/Cu films, where the $\mathrm{Cu}$ film functions as a catalyst for the formation of a graphite-like layer between the DLC and $\mathrm{Cu}$ films. The DLC/Cu film was synthesized on a Si (100) substrate via plasma-enhanced chemical vapor deposition and magnetron sputtering. The peelability, wear resistance, microstructure, texture, and cross-section of the film were experimentally analyzed. The results indicated a variation in the peelability with the deposition conditions of the $\mathrm{Cu}$ film that comprised particles with diameters of several nanometers. The DLC film at the interface in contact with the $\mathrm{Cu}$ film was transformed into a graphite-like state i.e., graphitized. The surface of the multilayered film exhibited antiseizure properties with the peeling of the upper DLC film. The multilayered film also exhibited wear resistance owing to the repeated appearances of a new DLC film. It is expected that the wear-resistant films with antiseizure properties demonstrated in the present study will be utilized in various industrial sectors.
\end{abstract}

Keywords: DLC film; graphite; peelability; multilayered film; wear resistance; antiseizure; chemical vapor deposition; magnetron sputtering

\section{Introduction}

Hot-press molding and injection molding are extensively utilized mass-production techniques owing to the recent advances in material development and production technology. However, the demand for resin moldings is continuously increasing owing to desirable features such as a high production efficiency and low environmental load. These features are attributed to the demolding resistance that is generated by the release of the molded product from the mold. The demolding resistance originates primarily from the molded resin wrapped around the undercut portion of the mold. The occurrence of adhesion wear and seizure is accompanied by mold stain because the resin remains on the mold [1]. Generally, mold-release agents are utilized to decrease the release resistance [2,3] and to cool the mold; however, the application of these agents is associated with certain drawbacks. To satisfy the dual functions, a substantial quantity of mold-release agents is required per molding. Most of the utilized quantity is discarded, thereby resulting in a high environmental load. The application of these agents also results in the existence of core pins with low diameters and high mold-release resistances owing to the uncoolable and shrinkage force of the resin. Therefore, the use of mold-release agents cannot prevent the occurrence of seizures [4]. It is necessary to lower the environmental load by developing 
a surface modification technique that imparts antiseizure properties. An increase in the mold-release performance will allow the molding of complicated shapes. Furthermore, the elimination of secondary processing after molding and an alleviation of the mold-release defects will facilitate the optimization of the production efficiency.

Diamond-like carbon (DLC) films are extensively utilized in various fields owing to their high hardness, low friction, chemical stability, and high wear resistance [5-11]. The amorphous DLC films comprise $\mathrm{sp}^{3}$-bonded carbon of diamond with a tetrahedral 3D-network structure, $\mathrm{sp}^{2}$-bonded carbon of graphite with a hexagonal structure, and hydrogen $[12,13]$. The characteristics of DLC vary with the $\mathrm{sp}^{2} / \mathrm{sp}^{3}$ bonding ratio of $C$ and $\mathrm{H}$ content $[5,14-16]$. DLC is typically prepared via chemical vapor deposition (CVD) [17] and physical vapor deposition (PVD) $[18,19]$.

Graphite consists of graphene sheets assembled in a honeycomb structure via the covalent bonding of $C$ atoms in $\mathrm{sp}^{2}$ hybrid orbitals $[13,20]$. It exhibits peelability and selflubrication properties owing to the weak van der Waals forces, instead of strong covalent bonds, between the graphene sheets [21]. The transformation at the interface of DLC films in contact with $\mathrm{Cu} / \mathrm{Ni}$ thin films into a graphene-like state has been reported in previous studies [22]. $\mathrm{Cu}$ is a transition metal with a closed-shell d-orbital, and the solid solubility of $\mathrm{C}$ in $\mathrm{Cu}$ is as low as 1-10 ppm. Furthermore, the interaction of $\mathrm{Cu}$ with $\mathrm{C}$ is extremely weak. The catalytic effect exerted by the dissociation of hydrocarbons and subsequent adsorption on $\mathrm{Cu}$ facilitates the formation of graphene [23]. The diffusion of the adsorbed C atoms to the surface is preferred in $\mathrm{Cu}$ over the precipitation reaction owing to temperature variations that occurs in Ni. The self-limiting effect of the reaction on the metal surface decreases the growth rate of graphene. This facilitates the synthesis of graphene with either a single layer or a controlled number of layers.

DLC, $\mathrm{Cr}, \mathrm{Cr} 3 \mathrm{C} 2$ and fluorinated materials films are utilized in demolding [24-27], and the coating of an injection-molding die with a DLC film induces an increase in the mold releasability [24]. Despite the application of those films, the molding of a highly viscous resin results in adhesion; consequently, the mold becomes dirty. The present study demonstrates the development of a functional surface film that not only retains the excellent characteristics of DLC but also exhibits wear resistance and antiseizure properties. A multilayered DLC/Cu film was synthesized via the alternate deposition of DLC and $\mathrm{Cu}$ films. Cu functioned as the catalyst for graphitization, and the outermost surface of the DLC film was partially graphitized at the interface with the $\mathrm{Cu}$ film. The synthesized multilayered film exhibited wear resistance and antiseizure properties owing to the alternate lamination of wear-resistant DLC films and peelable graphite layers.

\section{Materials and Methods}

\subsection{Deposition}

The DLC film was prepared via CVD. Here, a hydrocarbon gas (acetylene) was decomposed and ionized using a plasma at a low temperature $\left(<500{ }^{\circ} \mathrm{C}\right)$ to deposit the film. The $\mathrm{Cu}$ film was prepared via a PVD technique: magnetron sputtering. Here, an inert gas (Ar) was introduced in a vacuum chamber, and used a $\mathrm{Cu}$ target as a cathode. Thus, an Ar glow discharge plasma was formed on the target surface. The generated Ar ions collided with the target, flicked the target atom, and deposited the atom on the surface of the DLC film.

The experimental setup for the deposition of the DLC and $\mathrm{Cu}$ films on a Si substrate is shown in Figure 1. The electrode plate was hung from the top of the vacuum chamber using a Y-shaped jig. The distance between the electrode plate and the substrate was $130 \mathrm{~mm}$. The chamber pressure was initially decreased from atmospheric pressure to $10 \mathrm{~Pa}$ using a rotary pump (RP); subsequently, it was decreased to $5 \times 10^{-3}$ Pa using a turbo molecular pump (TMP). The pressure inside the chamber was regulated, even after introduction of the gas, by adjusting the opening/closing degree of the main exhaust valve (MV). 


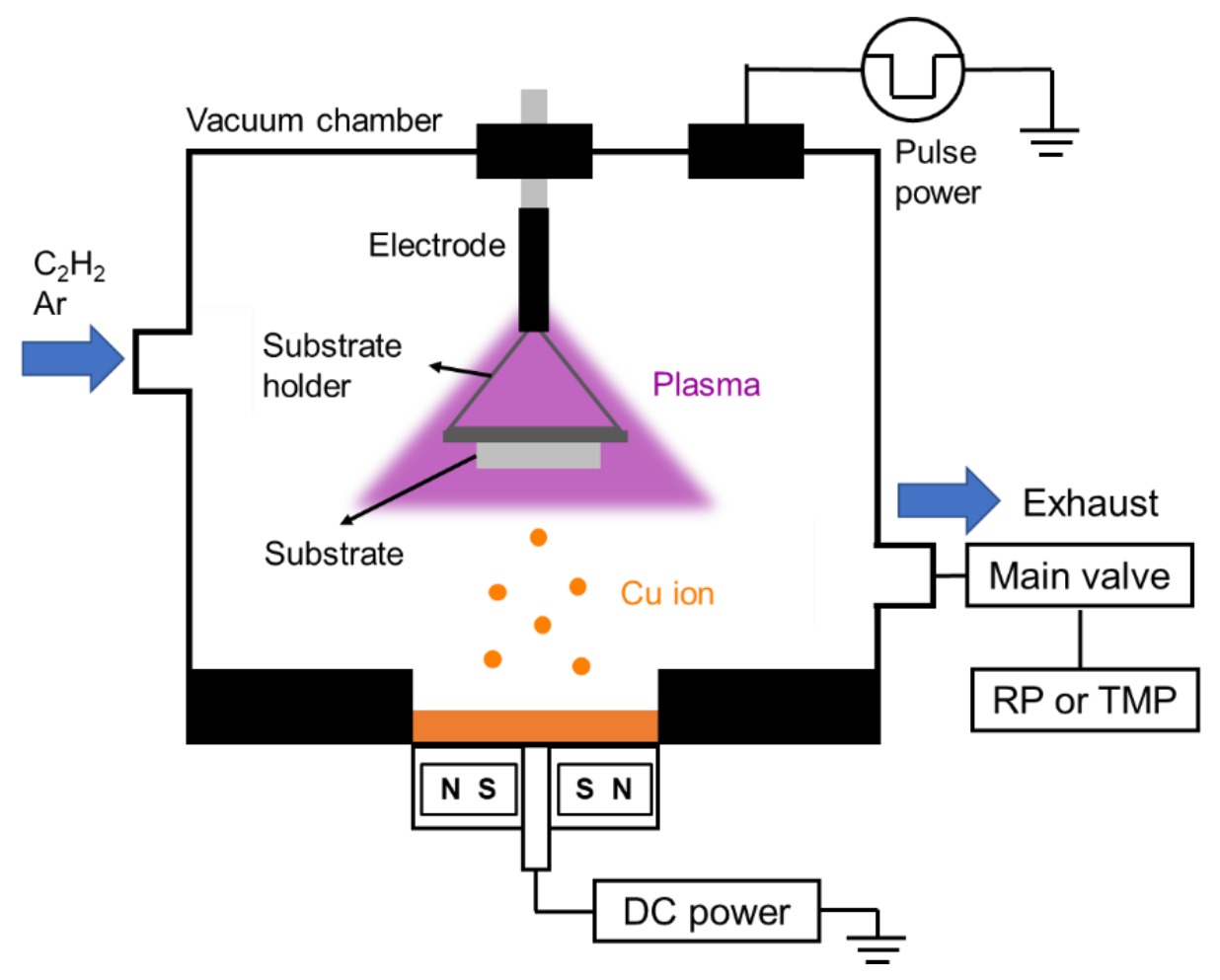

Figure 1. Schematic of the experimental setup.

Initially, Ar cleaning was performed for $30 \mathrm{~min}$ to increase the substrate temperature and eliminate the impurity films, such as the oxide film, on the substrate surface. Subsequently, the DLC film was synthesized using plasma CVD. The preparation time differed depending on the sample; therefore, the condition of each sample will be described later. The Cu film was synthesized via magnetron sputtering on the DLC film. A Cu target $(99.9 \%$ purity, Kojundo Chemical Lab. Co., Ltd., Sakado, Japan) was placed at the bottom of the chamber, and a voltage was applied for $5 \mathrm{~min}$. The shutter between the target and substrate was closed to eliminate the oxide film on the target surface via Ar pre-sputtering. The time at which the shutter was opened and voltage was applied was defined as the $\mathrm{Cu}$ sputtering start. Ar cleaning was not performed before the subsequent deposition of an additional DLC film on the $\mathrm{Cu}$ film. This was because the deposition was performed under identical vacuum conditions after $\mathrm{Cu}$ sputtering.

The $\mathrm{Cu}$ and DLC films were repeatedly synthesized using the above-mentioned method, based on the required number of films. The film-formation conditions are listed in Table 1, while the structures of the different samples are presented in Table 2.

Table 1. Conditions of cleaning, deposition, and sputtering.

\begin{tabular}{cccc}
\hline Conditions & Ar Cleaning & DLC Deposition & Cu Sputtering \\
\hline Source Gas & $\mathrm{Ar}$ & $\mathrm{C}_{2} \mathrm{H}_{2}$ & $\mathrm{Ar}$ \\
Pressure $(\mathrm{Pa})$ & 2.0 & 3.0 & 2.0 \\
Flow Rate $(\mathrm{sccm})$ & 20 & 20 & 20 \\
Bias Frequency $(\mathrm{kHz})$ & 14.4 & 14.4 & - \\
Bias Voltage $(\mathrm{kVp})$ & -3.5 & -4.0 & -0.38 \\
Current $(\mathrm{A})$ & - & - & 0.3 \\
Time & $30 \mathrm{~min}$ & $20 \mathrm{~min}$ & $15,20,25,50$, and $75 \mathrm{~s}$ \\
\hline
\end{tabular}


Table 2. Structures of various samples.

\begin{tabular}{ccc}
\hline Group & No. Films & Structures $^{*}$ \\
\hline A & 3 & DLC/Cu (300)/DLC \\
\hline B & 3 & DLC/Cu (X)/DLC \\
\hline C & 5 & DLC/Cu (25)/DLC/Cu (25)/DLC \\
\hline
\end{tabular}

* The numbers within parentheses after $\mathrm{Cu}$ indicate the deposition time (s) of the $\mathrm{Cu}$ film.

The bottom, third, and fifth films were designated as DLC I, II, and III, respectively, while the second and fourth films were designated $\mathrm{Cu}$ I and II, respectively.

Initially, some of the samples in group A were subjected to heat treatment at $500{ }^{\circ} \mathrm{C}$ to confirm the effect of temperature on the graphitization of the DLC film in contact with the $\mathrm{Cu}$ film. DLC films may react with $\mathrm{O}_{2}$ and undergo degradation during heating in atmospheric conditions; therefore, the heat treatment was performed in a $\mathrm{N}_{2}$ environment. The gas was introduced at $2.0 \times 10^{3} \mathrm{~cm}^{3} / \mathrm{min}$ for $30 \mathrm{~min}$, thereby filling the muffle furnace with $\mathrm{N}_{2}$ before heating. The heat-treated and non-heat-treated samples were designated as $\alpha$ and $\beta$, respectively.

The 3-layer samples in group $\mathrm{B}$ were prepared under different $\mathrm{Cu}$ deposition times i.e., $25(\mathrm{Cu}(25)), 50(\mathrm{Cu}(50))$, and $75 \mathrm{~s}(\mathrm{Cu}(75))$. The variation in the peelability with the thickness of the $\mathrm{Cu}$ film was investigated.

The $\mathrm{Cu}$ films were deposited under identical conditions for the 5-layer samples in group $\mathrm{C}$, and the properties of each layer were investigated.

Finally, we designed an 11-layer sample with a wear-resistant multilayer DLC coating by increasing the $\mathrm{Cu}$ deposition time, based on the basic results of the experiment. This sample consisted of $5 \mathrm{DLC} / \mathrm{Cu}$ layers, thus it was able to be resistant to repeated seizure 5 times.

\subsection{Film Evaluation}

\subsubsection{Structural Properties}

The particle shape and surface structure of the $\mathrm{Cu}$ film were observed using fieldemission scanning electron microscopy (FE-SEM) (S-5500, Hitachi High Technologies). To confirm the structure of graphene or graphite on the DLC film at the interface in contact with the $\mathrm{Cu}$ film, the cross-sectional structure was observed using high-resolution field-emission transmission electron microscopy (FE-TEM) (JEM-2100F, JEOL Ltd., Tokyo, Japan).

The structural variations of the DLC film were characterized using Raman scattering spectroscopy (inVia Raman microscope, Renishaw, Tokyo, Japan) [14]. The excitation laser has a wavelength of $532 \mathrm{~nm}$ and a grating of $1800 \mathrm{l} / \mathrm{mm}$. The laser output was $0.34[\mathrm{~mW}]$, the irradiation time was $1 \mathrm{~s}$, and the number of integrations was 20 . For the analysis of the obtained Raman spectrum, peak separation was performed using analysis software (WiRE 4.0, Renishow, Tokyo, Japan). A superimposed Raman spectrum, with the $G$ band at $1500-1600 \mathrm{~cm}^{-1}$ and $D$ band at approximately $1350 \mathrm{~cm}^{-1}$, was obtained from the amorphous $\mathrm{C}$ film. The $\mathrm{G}$ band was derived from the vibrations, including the cyclic and chain-like vibrations, of the $\mathrm{sp}^{2} \mathrm{C}-\mathrm{C}$ bonds. The $\mathrm{D}$ band was derived from the defects formed during the expansion and contraction vibrations of the six-membered ring primarily at the edges of the graphite clusters.

An increase in the $\mathrm{sp}^{3}$-bond ratio induced a shift in the central wavenumber of the $G$ band to the low-wavenumber side. Therefore, the integrated intensity ratio of the nuclear peak, i.e., $\mathrm{I}(\mathrm{D}) / \mathrm{I}(\mathrm{G})$, decreased. The full width at half maximum (FWHM) of the $\mathrm{G}$ band (FWHM (G)) represented the crystallinity of the graphite cluster. A highly crystalline structure corresponds to a sharp G band and a low $\operatorname{FWHM}(\mathrm{G})$. Furthermore, a disturbance in the structure induces an increase in FWHM (G) [28].

The Tuinstra-Koenig equation (Equation (1)) is related to $\mathrm{I}(\mathrm{D}) / \mathrm{I}(\mathrm{G})$ as an empirical equation for the grain size [15].

$$
\frac{I_{D}}{I_{G}}=\frac{560}{E_{L}} \frac{1}{L_{a}}
$$


Here, $E_{L}$ is the energy of the excitation light $[\mathrm{eV}]$ and $L_{a}$ is the size of the crystallite $[\mathrm{nm}]$ in the six-membered ring. The equation denotes that $\mathrm{I}(\mathrm{D}) / \mathrm{I}(\mathrm{G})$ is inversely proportional to the size of the graphite cluster. Therefore, it was possible to evaluate the structure and crystallinity of $C$ from the G-peak shift and either I(D)/I(G) or FWHM $(G)$.

The microstructure of the DLC film at the polar surface was investigated using surfaceenhanced Raman scattering (SERS) measurements. The SERS spectra were obtained based on the phenomenon of surface plasmon resonance (SPR). Metal (Ag) particles with a size of approximately $100 \mathrm{~nm}$ were adhered to the sample surfaces to calculate the Raman scattering intensity of the polar surface film. This allowed a detailed analysis of the film structure at the sample electrode surface [29]. The surface shape and roughness of the samples were observed using atomic force microscopy (AFM) (SPA300, Seiko Instruments Inc., Chiba, Japan) with a resolution in the nanometer range. The analysis was performed using the atomic force between the probe and samples.

\subsubsection{Mechanical Properties}

An instant adhesive was attached to the samples to evaluate the peelability of each DLC layer. The properties of the film interfaces were analyzed after peeling.

To quantify the peelability, the peeling force was measured using a micro load cell (LTS500GA, Kyowa Electronic Instruments Co., Ltd., Tokyo, Japan) attached to the pressurized part. The position was controlled using a servo press. A square sample $(10 \mathrm{~mm})$ was fixed to an acrylic plate using double-sided tape. A square cellophane tape $(10 \mathrm{~mm})$ was attached to the bottom of the jig, and the jig was contacted with the sample. The tensile load on the sample was measured, and the tape was peeled from the beginning until separation. The approach speed, pressing load, and release speed of the specimen and tape remained constant. The peeled area (A) was determined using image analysis software [30]. The energy required for peeling $(\mathrm{U})$ was obtained from the peeling force and displacement, and the adhesion resistance was calculated using the following equation: U/A.

The tribological characteristics, such as the friction coefficient and wear resistance, were evaluated using a ball-on-disk $(\mathrm{BoD})$ test, where the load was assumed to be applied during resin inflow. The vertical load owing to the weight was set to $0.5 \mathrm{~N}$, and the rotation speed was set to $100 \mathrm{rpm}$. The horizontal load was measured seven times within one rotation using a bearing steel ball (Japan standard, SUJ2, TSUBAKI NAKASHIMA CO., LTD., Katsuragi, Japan) with a diameter of $6 \mathrm{~mm}$. The median value of the seven measurements was considered as the friction coefficient for evaluation.

\section{Results and Discussion}

\subsection{FE-TEM Observations of the Cross-Sectional Structure of the Deposited Film}

The cross sections of the samples in group A, with and without heat treatment at $500{ }^{\circ} \mathrm{C}$, were observed via FE-TEM, and the images are presented in Figure 2.

The thickness of the DLC II film formed on the Cu film was higher than that of the DLC I film formed on the Si substrate. This was attributed to the adhesion between the deposited surface material and the DLC film. Generally, DLC films with internal stress exhibit stronger adhesion to $\mathrm{Si}$ than that to $\mathrm{Cu}$. This is because $\mathrm{Cu}$ is soft and susceptible to plastic deformation. $\mathrm{Cu}$ did not form carbides and bonds with $\mathrm{C}$; therefore, the density of the DLC I film was higher than that of the DLC II film.

The existence of porosity between the $\mathrm{Cu}$ and DLC films was detected in the samples subjected to heat treatment; however, no such porosity was detected in the samples without heat treatment. This was attributed to the thermal expansion and contraction of the $\mathrm{Cu}$ film during the heat treatment and subsequent cooling, respectively. The extent of expansion and contraction for the DLC film was less than that for the $\mathrm{Cu}$ film. Boubiche et al. reported that a metal catalyst facilitated the clustering of $\mathrm{sp}^{2}$ bonds throughout the DLC film along the orientation of the metal nucleus with an increase in the temperature [31]. Ilie et al. reported that heat treatment induced a transformation in the orientation of the $\mathrm{sp}^{2}$ clusters in the a(amorphous)-C film from vertical to parallel to the substrate. Consequently, there 
was an increase in the size of the graphite clusters [32]. This was attributed to a decrease in the adhesion of the interface and the wear resistance under heat treatment.

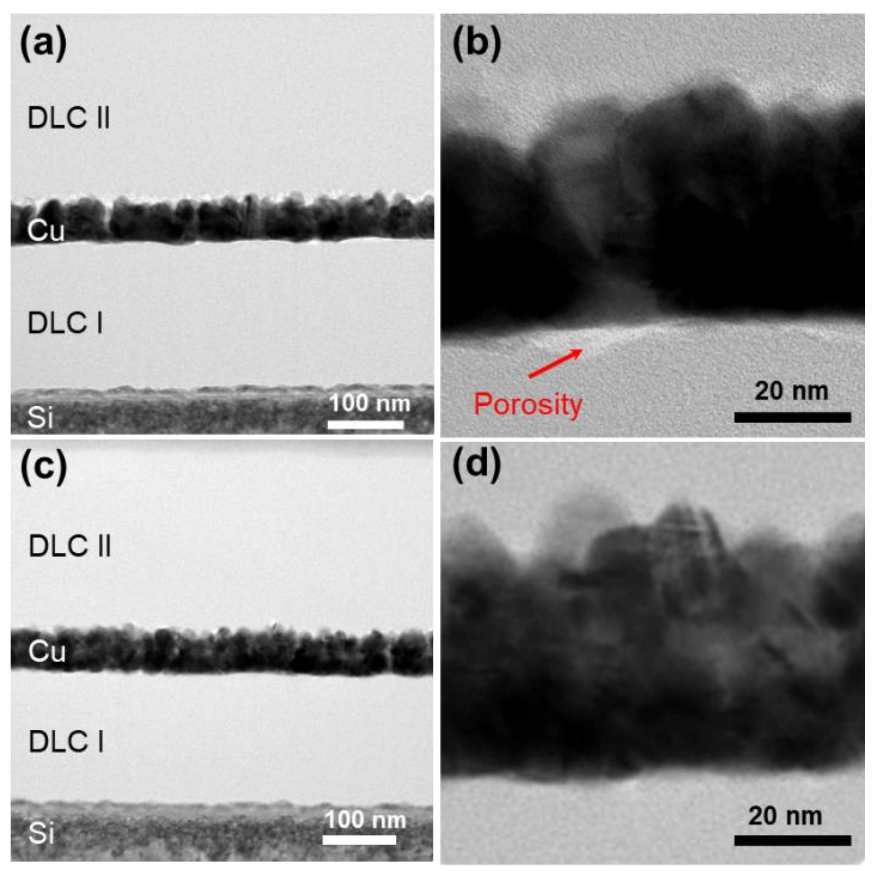

Figure 2. TEM (a) overview and (b) close-up view images of DLC/Cu (300)/DLC with heat treatment. TEM (c) overview and (d) close-up view images of DLC/Cu (300)/DLC without heat treatment.

Figure 3 presents the TEM images of the samples in groups $\mathrm{B}$ and $\mathrm{C}$ i.e., $\mathrm{DLC} / \mathrm{Cu}$ (50)/DLC and DLC/Cu (25)/DLC/Cu (25)/DLC, respectively. The sample interfaces presented different thicknesses, and the images in Figure 3a,c confirmed the 3-layer and 5-layer structures, respectively. The samples without heat treatment did not exhibit any porosity, unlike that for the samples subjected to heat treatment.
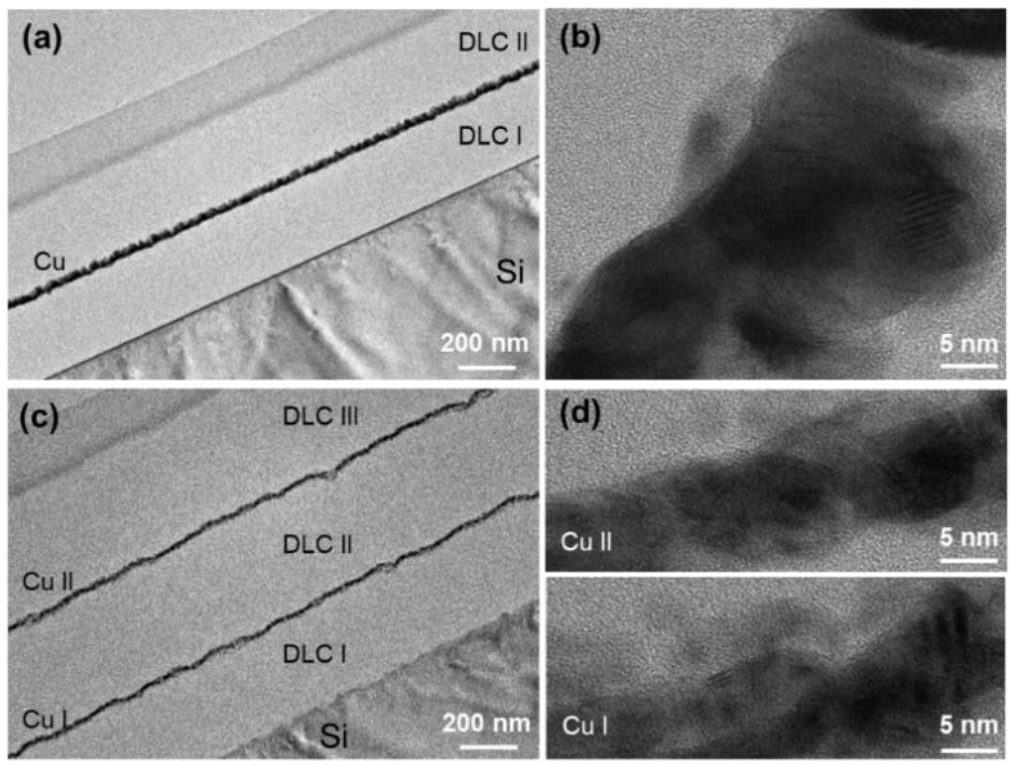

Figure 3. TEM (a) overview and (b) close-up view images of the 3-layer sample, DLC/Cu (50)/DLC, in group B. TEM (c) overview and (d) close-up view images of the 5-layer sample, DLC/Cu (25)/DLC/Cu (25)/DLC, in group C. 


\subsection{Structural Properties}

\subsubsection{Surface Observation of the Cu Film Using FE-SEM}

The surface structures of the $\mathrm{Cu}$ films, with different deposition times, for the samples in group B were observed via FE-SEM, and the images are presented in Figure 4a. The SEM images elucidated the effect of the thickness of the $\mathrm{Cu}$ film on the peelability. The particle size of $\mathrm{Cu}$ (25), $\mathrm{Cu}(50)$, and $\mathrm{Cu}(75)$ was approximately 15, 20, and $25 \mathrm{~nm}$, respectively. The diameter of the $\mathrm{Cu}$ particles increased with an increase in the $\mathrm{Cu}$ deposition time. This was ascribed to the condensation of nuclei into a large nucleus based on the Volmer-Weber model of film formation. Figure 5 shows the formation process of the nucleus in this model [33]. The Volmer-Weber growth of polycrystalline films involves the nucleation of $3 \mathrm{D}$ islands on a substrate surface and the subsequent growth, impingement, and coalescence of islands to form continuous films [34-36]. The thin-film growth techniques and growth conditions affect the grain shape, grain size distribution, and distribution of the crystallographic orientation of grains [37]. The variation in the stress-thickness product for different film thicknesses is attributed to the adatom-surface interaction energy [38]. The high mismatch between the DLC surface and $\mathrm{Cu}$ in the early stage of deposition facilitated film formation according to the Volmer-Weber model.

(a) SEM image of Cu surface in group $B$
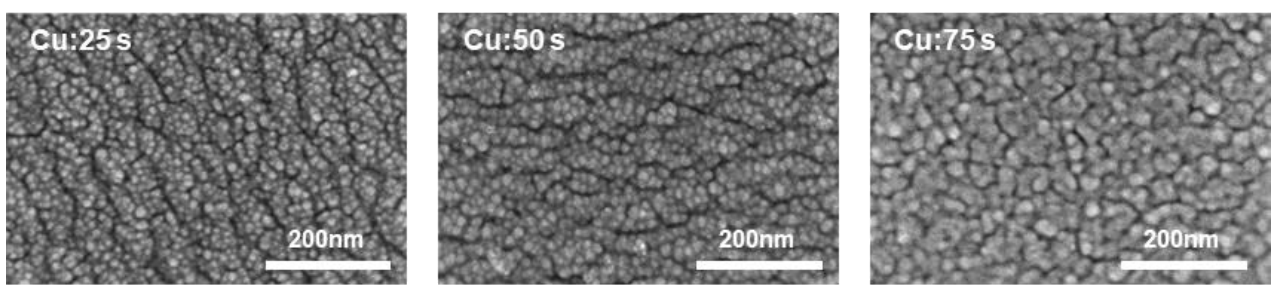

(b) SEM image of Cu surface in group $\mathrm{C}$
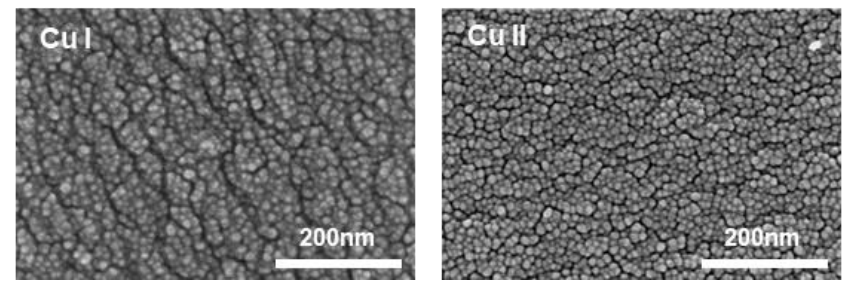

Figure 4. SEM images of the Cu surface for the samples in (a) group B and (b) group C.

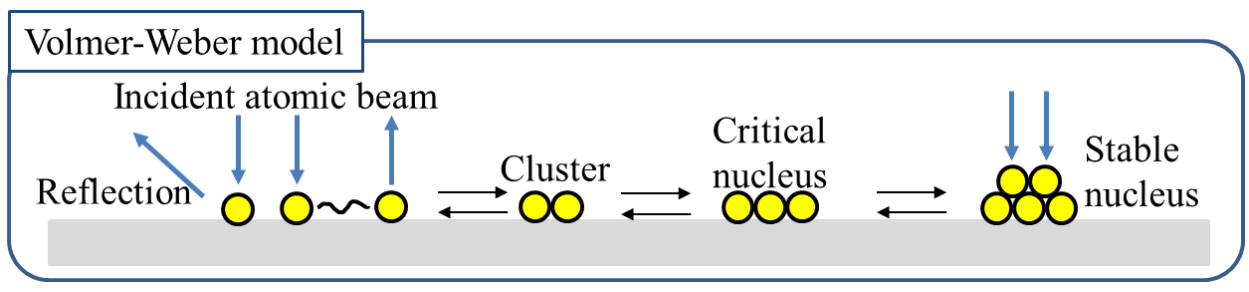

Figure 5. Formation of a nucleus in the Volmer-Weber model.

We also analyzed the crystal structures of the $\mathrm{Cu}$ I and II films for the samples in group $\mathrm{C}$ using FE-SEM, and the images are presented in Figure $4 \mathrm{~b}$. The $\mathrm{Cu}$ I and II films were synthesized under identical conditions with a deposition time of $25 \mathrm{~s}$. The particle size was approximately $10-15 \mathrm{~nm}$, and no significant differences in the size were observed. However, the 3D structure and growth exhibited by the $\mathrm{Cu}$ II film was more prominent and more advanced, respectively, as compared to those exhibited by the $\mathrm{Cu}$ I film. The sputtered particles of $\mathrm{Cu}$ collided with the DLC film, and the kinetic energy of the sputtered particles increased the temperature of the collision surface and the energy of the outermost layer of the DLC film. Zhou et al. fabricated a $20 \mathrm{~nm}$-thick $\mathrm{Cu}$ film on an $80 \mathrm{~nm}$-thick DLC 
film using a vapor deposition technique. They conducted elemental analysis via Auger molecular spectroscopy in the direction of the film thickness. The results indicated the diffusion of $\mathrm{C}$ atoms into the $\mathrm{Cu}$ film [39]. Dwivedi et al. identified the presence of $\mathrm{C}$ nanoaggregates with a network-like structure on the surface of a $\mathrm{C}: \mathrm{H}$ film formed on a $\mathrm{Cu}$ film. This indicated that $\mathrm{Cu}$ functioned as a catalyst and contributed to an increase in the $\mathrm{sp}^{2}$ bond content [40]. Therefore, the C atoms on the outermost surface of the DLC film diffused to form nanocrystal graphite.

\subsubsection{Microstructural Analysis of DLC Film Using Raman Scattering Spectroscopy and SERS}

Figure 6a shows the Raman spectra of the samples in group A. Initially, the spectra of the heat-treated sample were analyzed. The DLC II film presented slightly split peaks, while the spectra of DLC I film was not distinctly separated. The central wavenumber of the G peak for the DLC II film exhibited a tendency to shift to the high-wavenumber side. Therefore, the FWHM (G) and I(D)/I(G) for the DLC II film were lower and higher, respectively, than those for the DLC I film. This indicated that the proportion of $\mathrm{sp}^{2}$ bonds was higher in the DLC II film as compared to that in the DLC I film. An increase in the crystallinity of the graphite clusters was detected, thereby suggesting a structure similar to that of nanocrystal graphite. The analysis of the spectra for the non-heat-treated sample revealed that the DLC I and II films presented one broad peak with superimposed D and $\mathrm{G}$ bands. In addition, the occurrence of graphitization was not detected. The spectra of the heat-treated and non-heat-treated samples in group A were compared. The central wavenumber of the $G$ peak shifted to a higher level for $\alpha$ as compared to that for $\beta$. A decrease in the FWHM $(\mathrm{G})$ induced an increase in the $\mathrm{I}(\mathrm{D}) / \mathrm{I}(\mathrm{G})$ proportion of $\mathrm{sp}^{2}$ bonds, and crystallinity of the graphite clusters. This indicated that heat treatment promoted the graphitization of the DLC film.

Figure $6 \mathrm{~b}$ shows the SERS spectra of the samples for DLC/Cu (0), DLC/Cu (25)/DLC, and DLC/Cu (75)/DLC in group B. The samples under analysis were the DLC I films after peeling of the DLC II films. Although the deposition conditions of the DLC films were identical, the Raman spectra presented different features depending on the $\mathrm{Cu}$ deposition time. The central wavenumber of the $\mathrm{G}$ peak was ordered in the following sequence: $\mathrm{DLC} / \mathrm{Cu}(75) / \mathrm{DLC}>\mathrm{DLC} / \mathrm{Cu}(25) / \mathrm{DLC}>\mathrm{DLC} / \mathrm{Cu}(0)$. The shift in the central wavenumber to the high-wavenumber side became more pronounced with an increase in the $\mathrm{Cu}$ deposition time. This was attributed to an increase in the proportion of $\mathrm{sp}^{2}$ bonds. The central wavenumber of the G peak for DLC/Cu (75)/DLC was $1572 \mathrm{~cm}^{-1}$. This indicated that the DLC film at the surface was transformed to a structure similar to that of graphite. The FWHM (G) was ordered in the following sequence: DLC/Cu (75)/DLC < DLC/Cu $(25) / \mathrm{DLC}<\mathrm{DLC} / \mathrm{Cu}(0)$. This result revealed that the crystallinity of the graphite clusters in the DLC film increased with an increase in the $\mathrm{Cu}$ deposition time. The integrated intensity ratio $(\mathrm{I}(\mathrm{D}) / \mathrm{I}(\mathrm{G})$ ) was ordered in the following sequence: DLC/Cu (75)/DLC $>$ DLC/Cu (25)/DLC > DLC/Cu (0). This result confirmed that the crystallinity of the graphite clusters increased with an increase in the $\mathrm{Cu}$ deposition time. It was inferred, based on the aforementioned results, that the DLC film in the surface film was graphitized with an increase in the deposition time of the sputtered $\mathrm{Cu}$ film.

Figure $6 \mathrm{c}$ shows the SERS spectra of the DLC I and II films, after peeling, for the samples in group C. Although the deposition conditions of the $\mathrm{Cu}$ films were identical, the spectra revealed differences in the peak intensities. Both the DLC I and II films presented a broad peak with superimposed D and G peaks in conjunction with other sharp peaks at approximately $1600 \mathrm{~cm}^{-1}$. This was attributed to the summation of the $G$ and $\mathrm{D}^{\prime}$ peaks $[16,41]$. The $\mathrm{D}^{\prime}$ peak was ascribed to the vibration of the $\mathrm{sp}^{2} \mathrm{C}-\mathrm{C}$ bond of small graphite particles, thereby indicating the presence of nanocrystal graphite [16]. The structure of the DLC II film was more amorphous than that of the DLC I film owing to two factors. Firstly, the DLC film exhibited stronger adhesion to the Si substrate than that to the soft $\mathrm{Cu}$ film; therefore, the density of the DLC I film was higher than that of the DLC II film. Secondly, the adhesion of sputtered particles $(\mathrm{Ag})$ exerted a significant influence on the 
Raman spectra, except for the nanocrystal graphite film of the outermost surface at a depth of approximately 5-10 nm. The graphitization of the DLC film on the outermost surface progressed significantly on the first-peeled surface. This was attributed to an increase in the substrate temperature with the progress of deposition, thereby resulting in a high-intensity D' peak.

(a) group A.
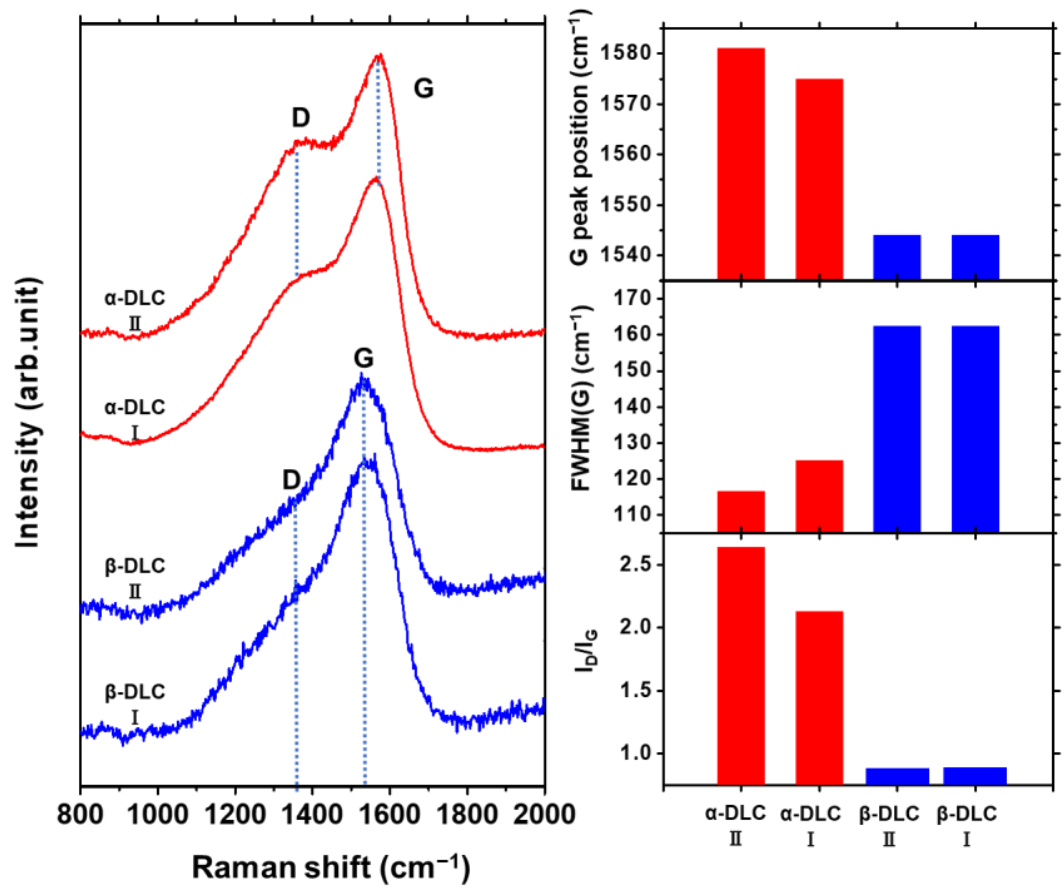

(b) group B.
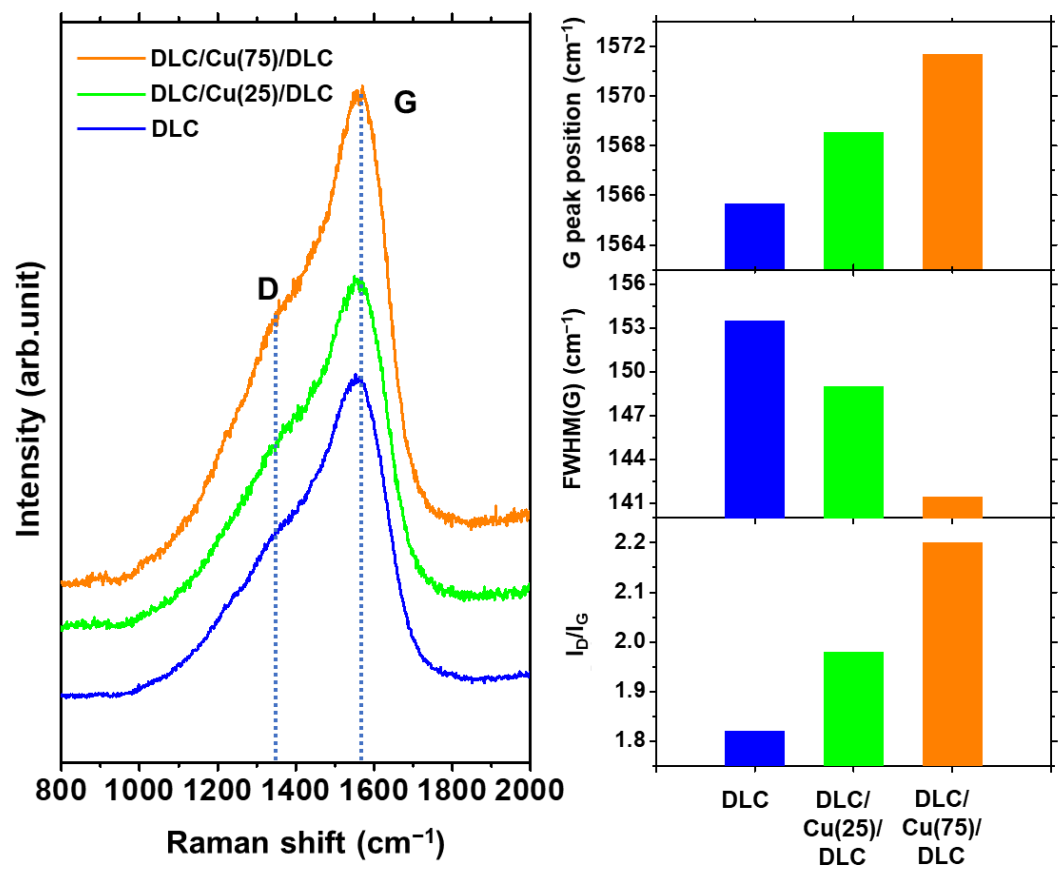

Figure 6. Cont. 
(c) group C.
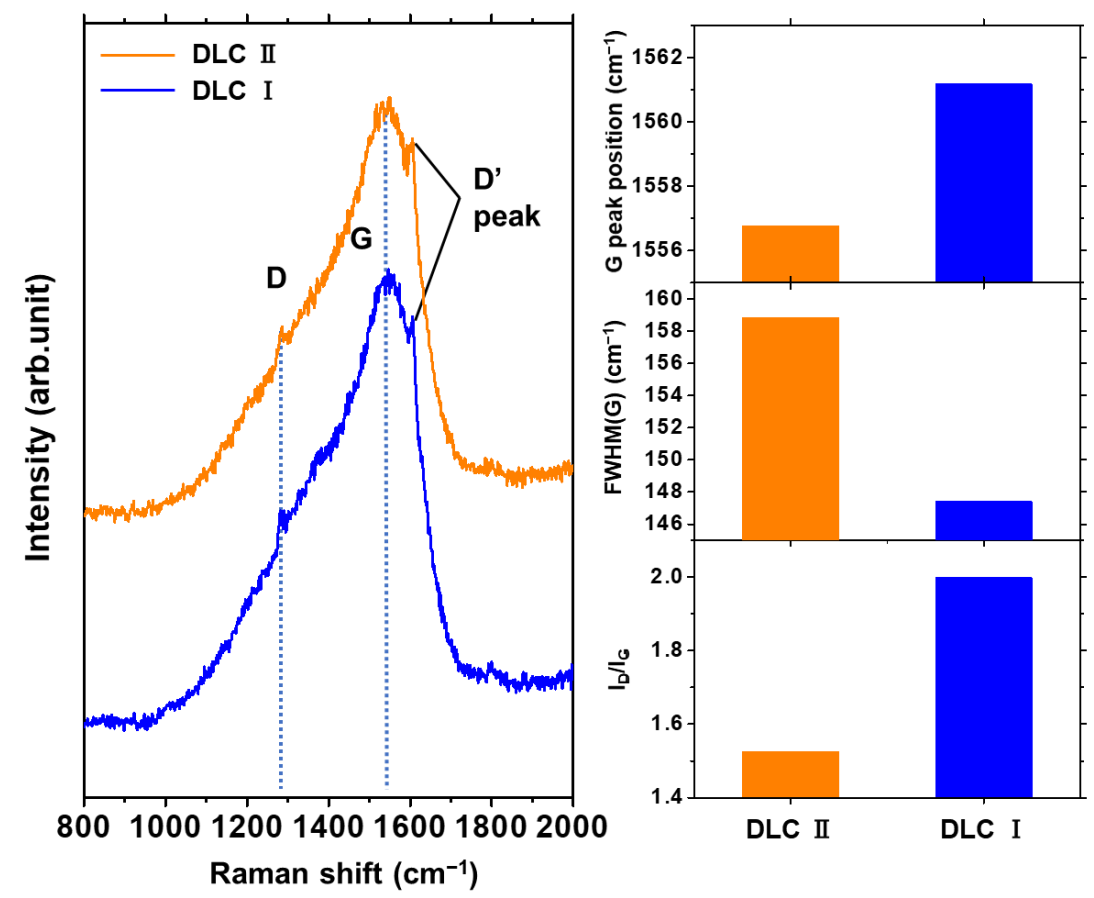

Figure 6. (a) Raman spectra and Raman parameters of the DLC I films for the samples in group A. (b) Raman spectra and Raman parameters for DLC/Cu(X)/DLC in group B. (c) Raman spectra and Raman parameters of the DLC I and II films, after peeling, for the samples in group C.

\subsubsection{Observation of the Surface Roughness Using AFM}

The surface shape and roughness of the samples in group $C$ were evaluated using AFM, and the results are presented in Figure 7a-e and Table 3. Although the DLC films were deposited under identical conditions, the roughness and thickness of the DLC I film were significantly lower than those of the DLC II and III films. This was attributed to the high density of the DLC I film that adhered to the Si substrate. The surface roughness of the DLC II and III films were $5.36 \mathrm{~nm}$ and $5.14 \mathrm{~nm}$, respectively. The Cu particles impacted the surface of the DLC II film during the formation of the $\mathrm{Cu}$ II film. This collision resulted in the higher roughness of the DLC II film as compared to that of the DLC III film. The roughness and contact area of the $\mathrm{Cu}$ II film were higher than those of the $\mathrm{Cu}$ I film. This was because the $\mathrm{Cu}$ II film was formed on the DLC II film that was rougher than the DLC I film. The extent of graphitization of DLC induced by the $\mathrm{Cu}$ II film was higher than that induced by the $\mathrm{Cu}$ I film. Therefore, the upper DLC/Cu interface was expected to exhibit high peelability.

Table 3. Roughness and thickness of the films for the samples in group C.

\begin{tabular}{ccc}
\hline Films & Roughness $\mathbf{( n m )}$ & Thickness $(\mathbf{n m})$ \\
\hline DLC III & 5.14 & 180 \\
Cu II & 10.13 & 19 \\
DLC II & 5.36 & 178 \\
Cu I & 5.90 & 16 \\
DLC I & 1.94 & 124 \\
\hline
\end{tabular}




\section{DLC}
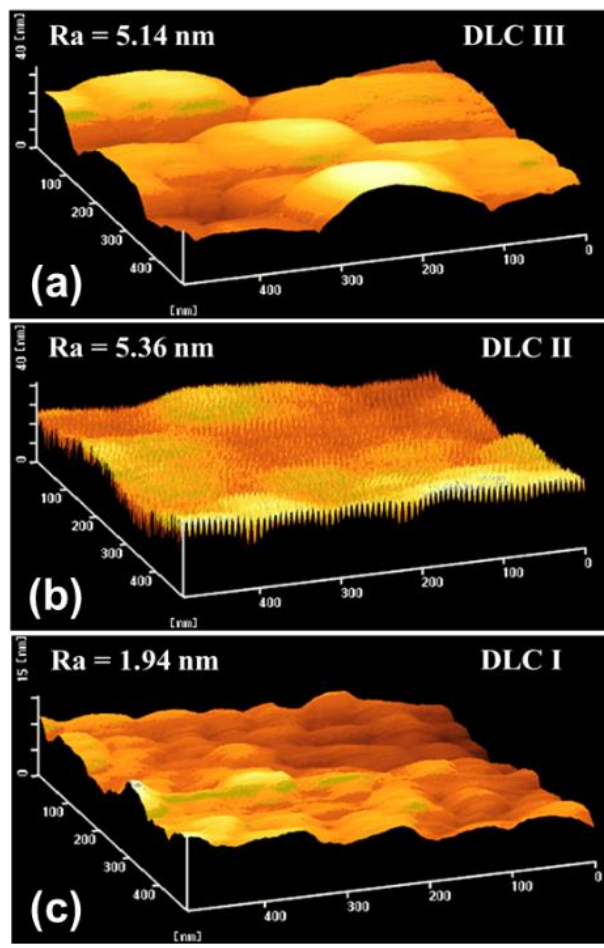

$\mathrm{Cu}$
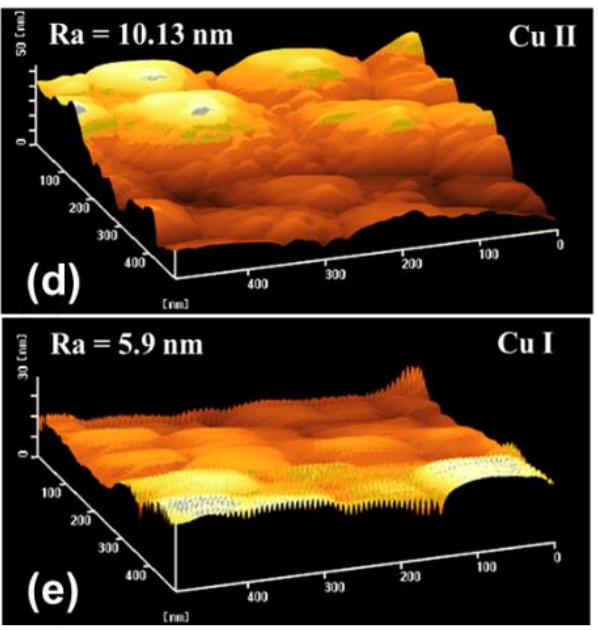

Figure 7. Surface shapes and roughness of the (a) DLC III, (b) Cu II, (c) DLC II, (d) Cu I, and (e) DLC I films for the samples in group C.

\subsection{Mechanical Properties}

\subsubsection{Evaluation of Peelability via Measurement of Peeling Force}

Cellophane tape was attached to the upper film of the prepared sample and peeled off to determine whether peeling was possible. As shown in Figure 8a,b, a brown Cu film was observed on the peeled surface and tape side, while the DLC film was observed on the substrate side of the samples in groups A and B. This indicated the occurrence of peeling at the DLC I/Cu interface. The positions of all the samples and tapes were fixed, and there were no significant differences in the measurement area. DLC/Cu (15), (20)/DLC exhibited incomplete peeling, whereas DLC/Cu (25)/DLC exhibited uniform peeling. Therefore, the optimal deposition time was determined to be 20-25 s. The brown $\mathrm{Cu}$ films adhered to the peeling tape side, while the glossy DLC films adhered to the substrate side of the samples in group $C$ during the first and second peeling shown in Figure $8 \mathrm{c}$. This confirmed the successful fabrication of a twice-peelable structure.

The results of the peeling force test, i.e., peeling energy, peeled area, and peeling energy per unit area (adhesion energy), are presented in Table 4. Figure 9a shows the relation between the displacement from the peeling start point and the tensile force for the samples in group $A(\alpha$ and $\beta$ ). The adhesion energy of $\alpha$ was approximately $1 / 10$ th of that of $\beta$. The existence of porosity owing to heat treatment resulted in the high peelability of $\alpha$.

Figure $9 \mathrm{~b}$ shows the relation between the displacement from the peeling start point and the tensile force for the samples in group B. The peeling energy of the samples in group $\mathrm{B}$ was higher than that of the samples in group A. A decrease in the $\mathrm{Cu}$ deposition time induced an increase in the adhesion of the DLC/Cu interface. A comparison of $\mathrm{Cu}(75)$, $\mathrm{Cu}(50)$, and $\mathrm{Cu}(25)$ revealed a decrease in the adhesion energy with an increase in the $\mathrm{Cu}$ deposition time. 

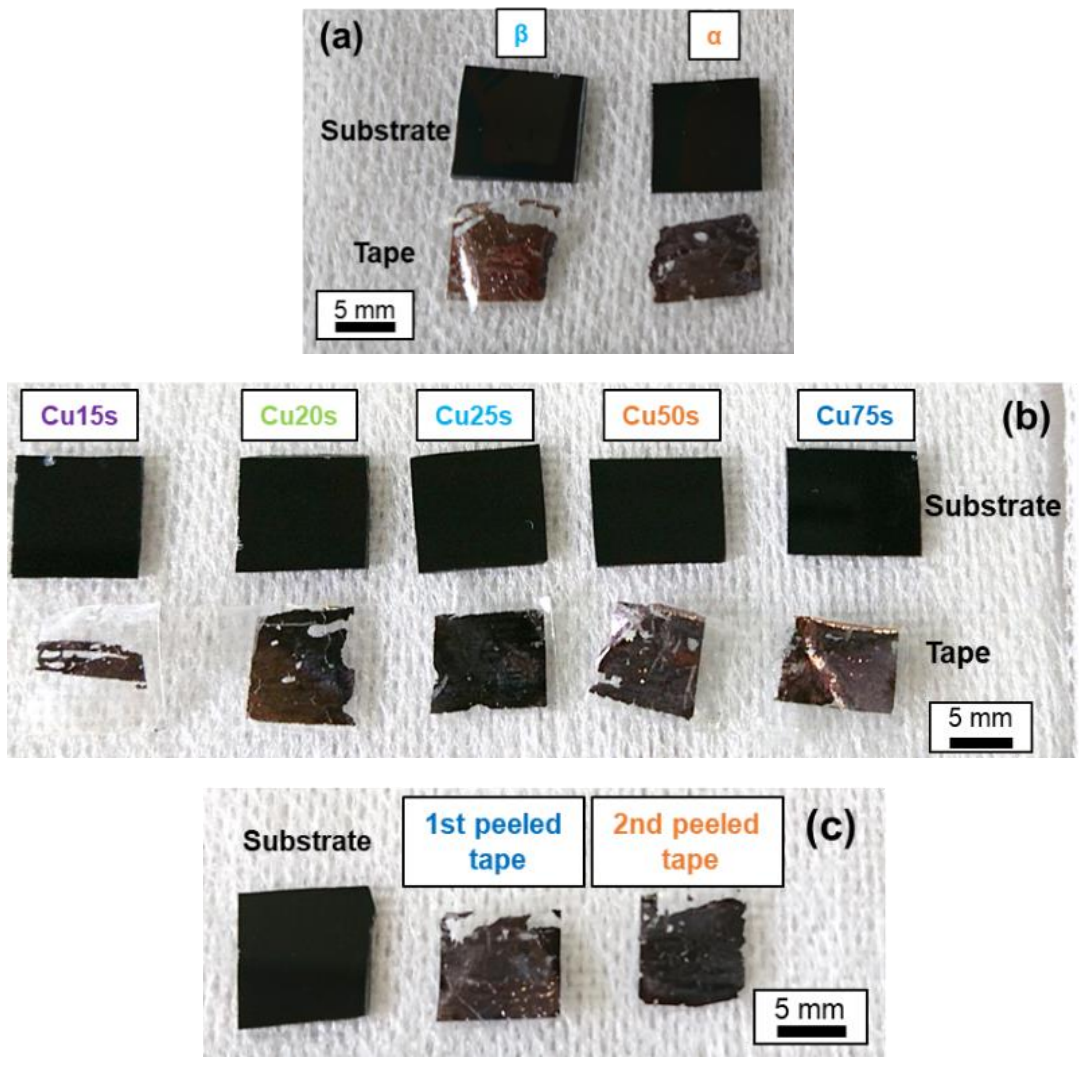

Figure 8. Appearance of samples in (a) group A, (b) group B, and (c) group C.

Table 4. Peeling properties of the samples in each group.

\begin{tabular}{|c|c|c|c|c|c|}
\hline \multicolumn{3}{|c|}{ Specimens } & $\begin{array}{c}\text { Peeling } \\
\text { Energy (U) }\end{array}$ & $\begin{array}{c}\text { Peeled Area } \\
\text { (A) }\end{array}$ & $\begin{array}{c}\text { Adhesion } \\
\text { Energy (U/A) }\end{array}$ \\
\hline \multirow{2}{*}{ Group A } & \multicolumn{2}{|c|}{$\alpha:$ With $500{ }^{\circ} \mathrm{C}$ heat treatment } & $5.21 \times 10^{-4}$ & $8.90 \times 10^{-5}$ & 5.86 \\
\hline & \multicolumn{2}{|c|}{$\beta:$ Without heat treatment } & $5.23 \times 10^{-3}$ & $8.55 \times 10^{-5}$ & 61.1 \\
\hline \multirow{3}{*}{ Group B } & \multicolumn{2}{|c|}{$\mathrm{DLC} / \mathrm{Cu}(25) / \mathrm{DLC}$} & $11.5 \times 10^{-3}$ & $6.02 \times 10^{-5}$ & 191 \\
\hline & \multicolumn{2}{|c|}{$\mathrm{DLC} / \mathrm{Cu}(50) / \mathrm{DLC}$} & $9.66 \times 10^{-3}$ & $7.00 \times 10^{-5}$ & 138 \\
\hline & \multicolumn{2}{|c|}{$\mathrm{DLC} / \mathrm{Cu}(75) / \mathrm{DLC}$} & $2.83 \times 10^{-3}$ & $5.44 \times 10^{-5}$ & 52.0 \\
\hline \multirow{2}{*}{ Group C } & \multirow{2}{*}{$\begin{array}{c}\text { DLC/Cu } \\
(25) / \mathrm{DLC} / \mathrm{Cu} \\
(25) / \mathrm{DLC}\end{array}$} & First peeling & $2.44 \times 10^{-3}$ & $6.76 \times 10^{-5}$ & 36.1 \\
\hline & & Second peeling & $9.70 \times 10^{-3}$ & $6.15 \times 10^{-5}$ & 158 \\
\hline
\end{tabular}

Figure $9 \mathrm{c}$ shows the relation between the displacement from the peeling start point and the tensile force for the samples in group C. The peeling energy at the DLC I/Cu I interface was approximately equal to the peeling energy of $\mathrm{Cu}(25)$ in group B. Although the $\mathrm{Cu}$ I and II films were synthesized under identical conditions, the peeling energy at the $\mathrm{Cu}$ II/DLC II interface was calculated to be lower than that at the DLC I/Cu I interface. The results of the peeling force test in conjunction with the AFM observations revealed that a high surface roughness induced an increase in the peelability of the upper interfaces. 

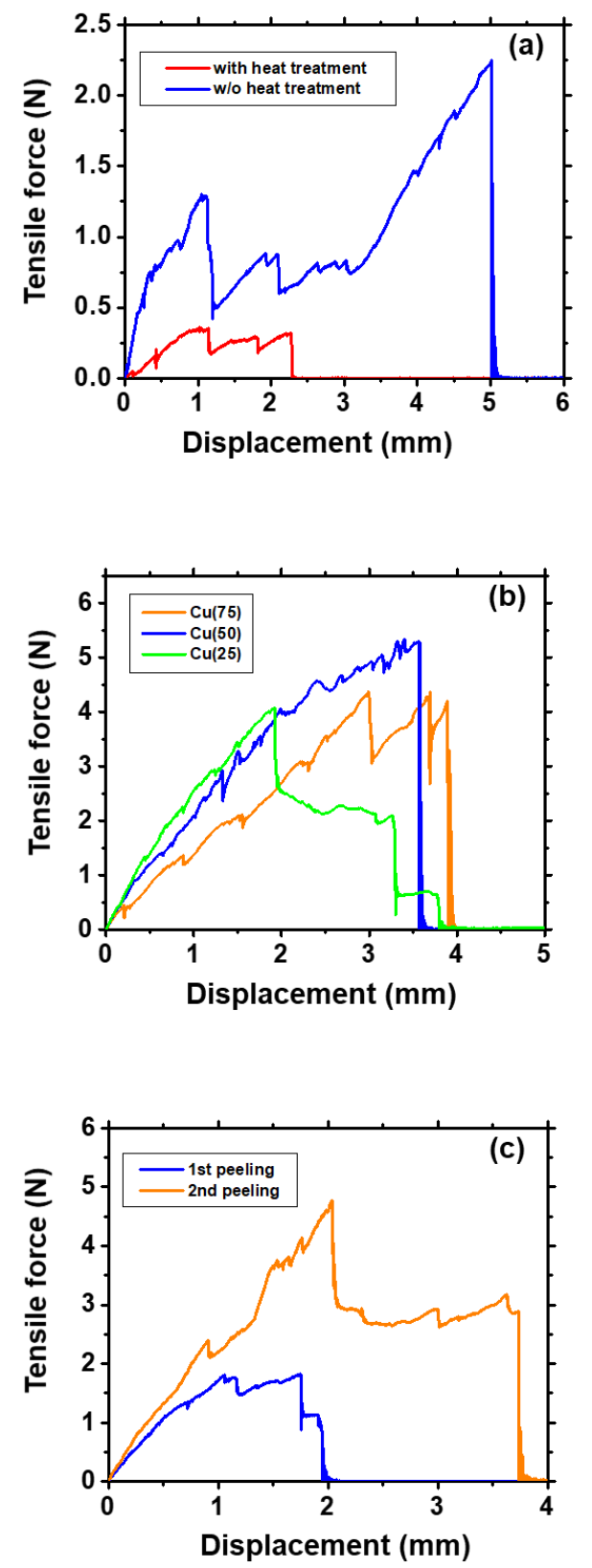

Figure 9. Results of the peeling force test for the samples in (a) group A, (b) group B, and (c) group C.

\subsubsection{Evaluation of Wear Resistance via BoD Test}

Figure 10 presents the results of the BoD test for the samples in group A. The friction coefficient of $\alpha$ was approximately 0.2 at the beginning of sliding, and it increased after 12 rotations. The friction coefficient after 200 rotations (0.6) was equivalent to the friction coefficient between the Si substrate and SUJ2. A substantial quantity of wear powder was generated in the initial stage of sliding. Therefore, the upper DLC II film was damaged after approximately 10 rotations; furthermore, the DLC I film underwent wear after 200 rotations because the Si substrate was exposed. The friction coefficient of $\beta$ was maintained at approximately 0.05 in the initial stage of sliding. It increased after approximately 100 rotations owing to the wear of the upper DLC II film and $\mathrm{Cu}$ film; finally, the friction coefficient stabilized at 0.2 owing to the exposure of the DLC I film. The friction coefficient at the initial stage of sliding was as low as 0.1 because the $\mathrm{Cu}$ thin film was softer than the Si substrate. The DLC film underwent pressure relaxation owing to elastic deformation, thereby resulting in a lowering of the friction coefficient. Li et al. compared the results of the sliding tests for a DLC film formed on a Si substrate and a DLC film formed on a $\mathrm{Cu}$ 
substrate. They reported a decrease in the friction coefficient owing to the deformation of the soft $\mathrm{Cu}$ substrate [42]. These results indicated that heat treatment induced a marked decrease in the wear resistance.

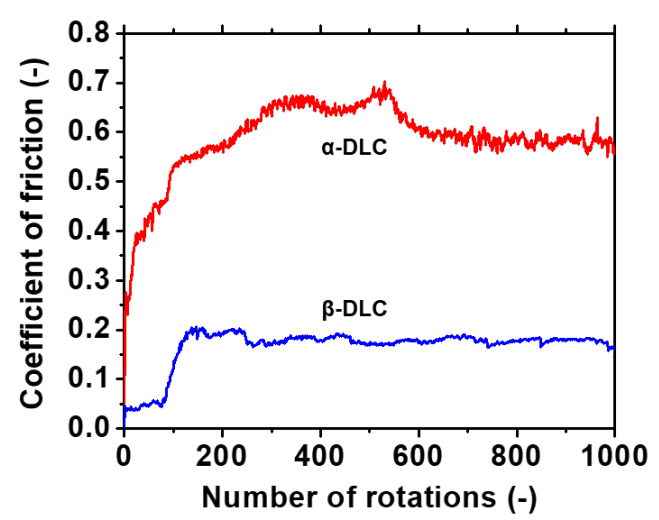

Figure 10. Results of the BoD test for the heat-treated $\left(25^{\circ} \mathrm{C}, 46 \% \mathrm{RH}\right)$ and non-heat-treated $\left(27^{\circ} \mathrm{C}\right.$, $54 \% \mathrm{RH})$ samples in group A.

Figure 11 presents the results of the BoD test for the samples in groups $\mathrm{B}$ and $\mathrm{C}$. The friction coefficient of DLC/Cu (75)/DLC was maintained at approximately 0.1 after approximately 300 rotations. Subsequently, it increased to approximately 0.2 owing to the generation of substantial wear debris and finally stabilized. Figure 12 shows the sliding surface after 300 and 5000 rotations. The presence of a storied structure at the boundary, where the upper DLC II/Cu I film did and did not undergo wear, resulted in exposure of the DLC I film.
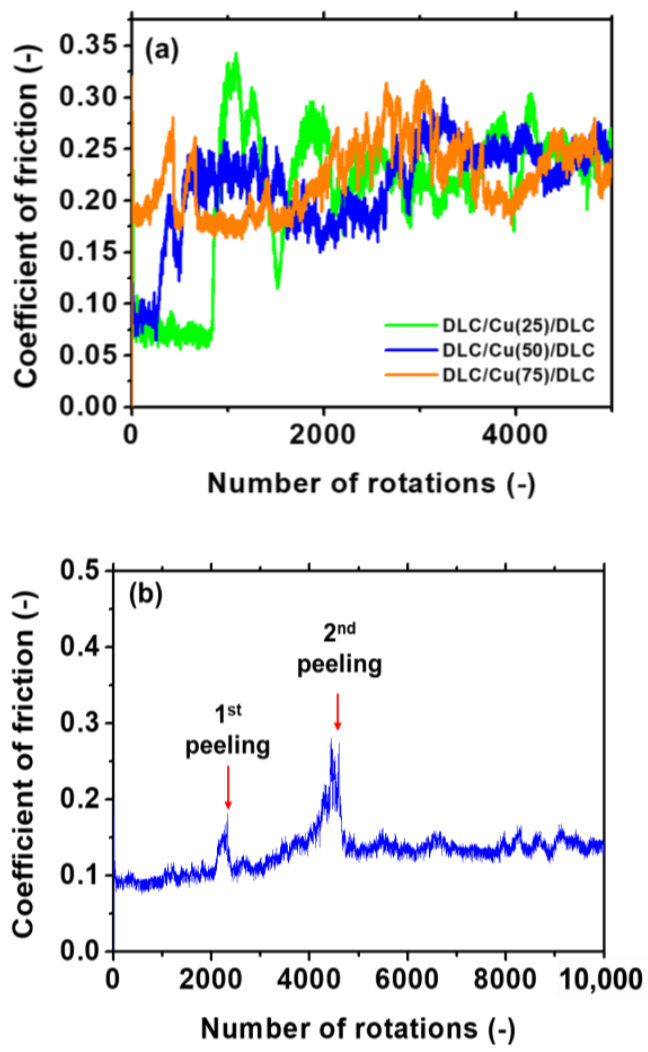

Figure 11. Results of the BoD test for the samples in (a) group B and (b) group C. 


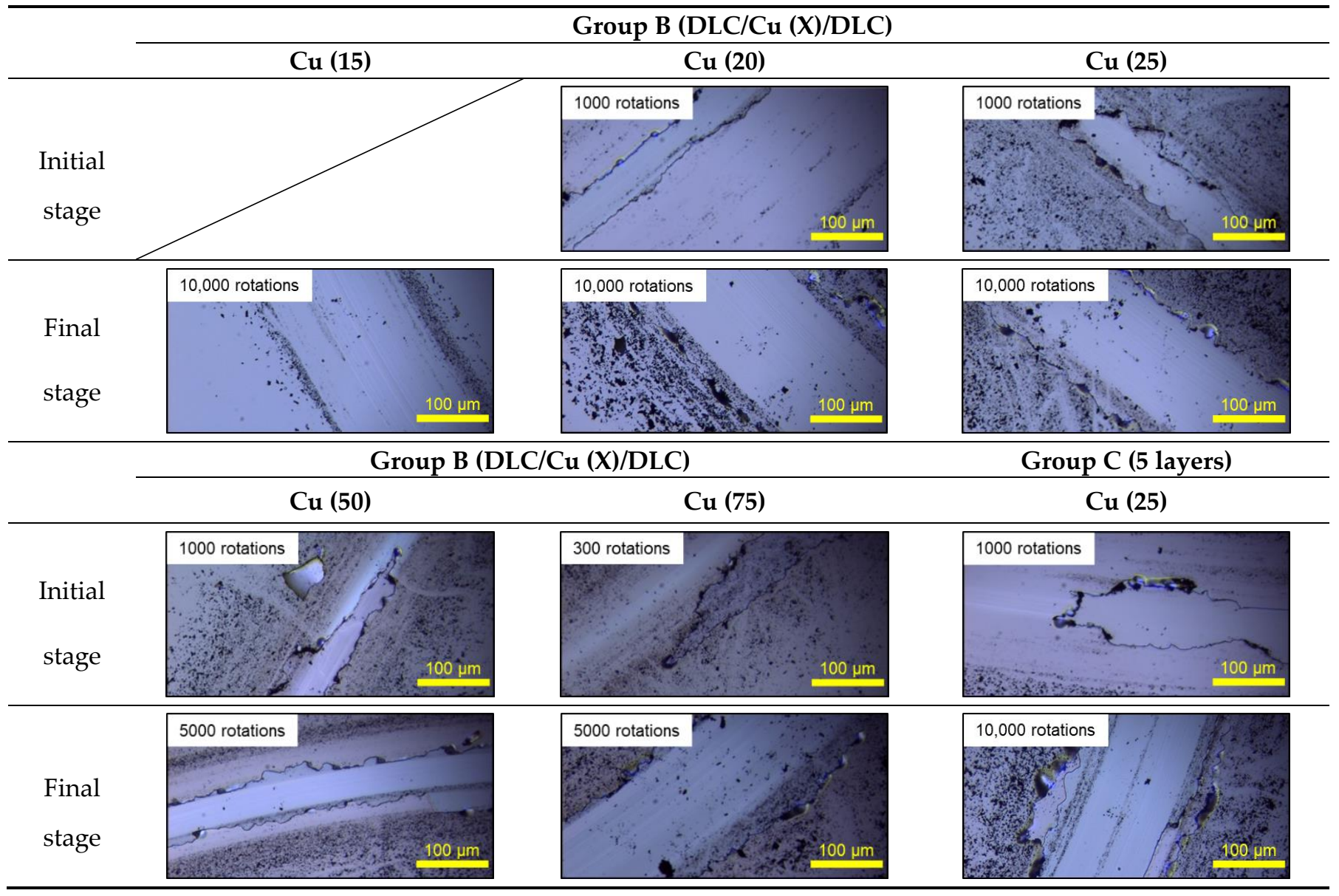

Figure 12. Images of the wear track of the films.

DLC/Cu (50)/DLC and DLC/Cu (75)/DLC exhibited similar friction coefficients at the beginning of sliding. There was a gradual increase in the friction coefficient after approximately 1200 rotations to approximately 0.4 . The exposed DLC I film was narrow and exhibited a wavy fracture surface. The gradual increase in the friction coefficient was attributed to the continuous generation of wear powder.

There was a significant increase in the friction coefficient of DLC/Cu (25)/DLC after approximately 1000 rotations. Subsequently, the friction coefficient exhibited an unstable state till approximately 6000 rotations. Finally, a stable friction coefficient of approximately 0.3 was obtained.

Figure 12 presents the sliding mark for the samples in group B, i.e., DLC/Cu (15), (20)/DLC, over 10,000 rotations. The DLC II film was abraded after the initial 1000 rotations. The DLC I film was exposed completely after 10,000 rotations because the upper DLC film was damaged. The quantity of black wear powder for these samples was lower than that for the other samples. The low quantity of the wear powder resulted in stable friction.

The initial friction coefficient for the samples in group $C$ was approximately 0.1 , which was similar to the friction coefficient of DLC/Cu (25)/DLC in group B. Two peaks were observed after 2200 and 4500 rotations in Figure 11b. The friction coefficient raised at 2200 rotations inferred that the DLC III film had worn out and Cu II layer was exposed. Then it went back to 0.1 immediately, which inferred the DLC II film was exposed due to the abrasion of $\mathrm{Cu}$ II layer. A similar phenomenon occurred at 4500 rotations. After that, the friction coefficient remained stable revealing that the entire 5-layer film was able to bear till 10,000 rotations. Figure 12 shows the sliding track at the end of the test after 10,000 rotations. A three-story structure was detected at the edge of the sliding mark. The DLC I film was eventually exposed owing to the gradual wear of DLC III/Cu II and DLC II/Cu I. 
In samples DLC/Cu (20), (25)/DLC, the width of 1000 rotations were approximately $50 \mu \mathrm{m}$, and appeared approximately $165 \mu \mathrm{m}$ after 10,000 rotations. The variation of time intervals between samples DLC/Cu (20)/DLC and DLC/Cu (25)/DLC were so small that no significant difference was observed. However, the width was approximately $50 \mu \mathrm{m}$ in DLC/Cu (50)/DLC, approximately $170 \mu \mathrm{m}$ in DLC/Cu (75)/DLC after 5000 rotations. It is considered that the wear resistance decreased as the copper deposition time increased.

\subsection{Fabrication of the 11-Layer DLC Film}

Figure 13 shows the appearance of the films after peeling. Although the films were not uniformly peeled, the peelability of certain parts (within the range of the red dotted line) was five times of that of the upper film. The initially unpeeled area was peeled after the second peeling till the sixth peeling. The negligible differences in the peelability of each film set resulted in nonuniform peeling. These results indicated the dependence of the peelability on the $\mathrm{Cu}$ deposition time; in addition, they demonstrated the successful prevention of repeated seizures.

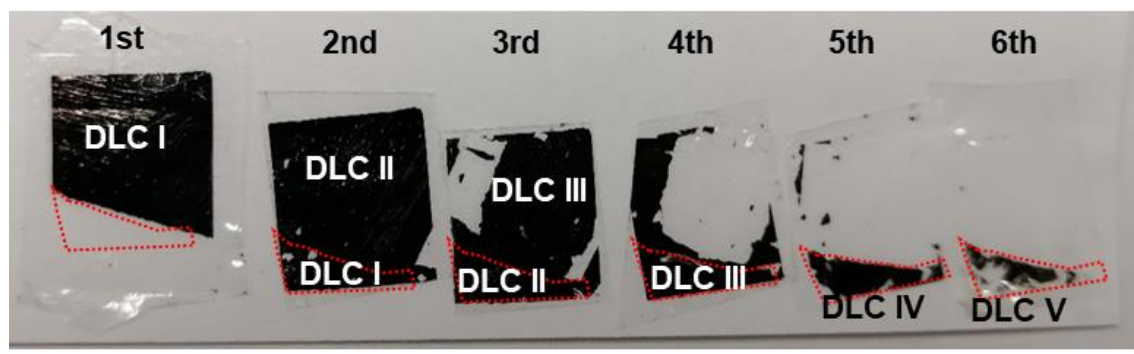

Figure 13. Appearance on the tapes of the 11-layer films after peeling.

An increase in the number of films resulted in an increase in the production time. This was attributed to the requirement of cooling time. An additional increase in the number of peelings was expected to be difficult. It was inferred, considering the practical applications of the mold, that the shape of the molded product was dependent on the thickness of the deposited film on the mold surface; furthermore, the molding accuracy was dependent on the thickness of the DLC/Cu films.

\section{Conclusions}

The present study demonstrated the synthesis of multilayered DLC films via CVD and magnetron sputtering. The synthesized films with a DLC/Cu/DLC structure exhibited antiseizure properties that prevented the adhesion of instant adhesives. The appearance of the DLC film after peeling allowed the retention of wear resistance, and this indicated the successful development of a functional coating. The peeling interface of the film was subjected to SERS analysis. The results revealed that the deposition of the $\mathrm{Cu}$ film via magnetron sputtering induced the transformation of the DLC film at the polar interface into nanocrystal graphite.

Heat treatment induced an increase in the peelability. However, the existence of porosity at the $\mathrm{Cu} / \mathrm{DLC}$ interface resulted in a significant decrease in the wear resistance. An increase in the $\mathrm{Cu}$ deposition time also induced an increase in the peelability. However, the load capacity in the shear direction of the $\mathrm{Cu}$ /DLC interface was lowered, and the occurrence of surface fracture owing to peeling was highly probable. This resulted in a decrease in the wear resistance. Both $\mathrm{Cu}$ films in the 5-layer sample (group $\mathrm{C}$ ) were prepared simultaneously; however, the peeling energy at the upper Cu II/DLC II interface was lower than that at the DLC I/Cu I interface. All the DLC surfaces remained wear resistant for more than 1000 rotations in the BoD test.

The characteristics at the interface varied depending on the thickness of the $\mathrm{Cu}$ film and the stacking order of the DLC film. Therefore, it was possible to synthesize multilayered DLC films capable of withstanding more than 1000 cycles of sliding. 
The effects of the distance between the substrate and target, bias voltage, and current during $\mathrm{Cu}$ sputtering on the peelability were not investigated in the present study. However, these parameters induced a variation in the energy of the sputtered particles, thereby affecting the graphitization of the DLC film at the polar interface. Therefore, the sputtering parameters can be considered as controlling factors for the peelability.

Future research on this subject may be conducted on the following topics:

(1) Thinning of DLC films.

(2) Determination of the correlation between the substrate temperature and the peelability.

(3) Control of the peelability using other parameters.

Author Contributions: Conceptualization, N.O.; methodology, N.O.; investigation, J.E. and Y.L.; data curation, J.E. and Y.L.; writing-review and editing, Y.L. and Y.H.; supervision, Y.H., H.A. and N.O.; project administration, N.O.; funding acquisition, N.O. All authors have read and agreed to the published version of the manuscript.

Funding: This work was supported by JSPS KAKENHI Grant numbers 20K21078, 16 H02406.

Institutional Review Board Statement: Not applicable.

Informed Consent Statement: Not applicable.

Data Availability Statement: The data presented in this study are available on request from the corresponding author.

Acknowledgments: The authors thank the Materials Analysis Division, Open Facility, Tokyo Institute of Technology, for FE-TEM and FE-SEM analysis. Raman analysis was supported by the Collaboration Center for Design and Manufacturing, Tokyo Institute of Technology.

Conflicts of Interest: The authors declare no conflict of interest.

\section{References}

1. Murata, Y.; Nakanishi, T.; Hirai, N.; Kawanishi, F.; Ibuki, H. Development of Mold for Demolding Resistance Measurement in Polymer Injection Molding. Sens. Mater. 2019, 31, 3099. [CrossRef]

2. Wang, C.-F.; Chiou, S.-F.; Ko, F.-H.; Chen, J.-K.; Chou, C.-T.; Huang, C.-F.; Kuo, S.-W.; Chang, F.-C. Polybenzoxazine as a Mold-Release Agent for Nanoimprint Lithography. Langmuir 2007, 23, 5868-5871. [CrossRef]

3. Yamamoto, H.; Ohkubo, Y.; Ogawa, K.; Utsumi, K. Application of chemically adsorbed fluorocarbon film with highly durability as a mold release agent. Seikei-Kakou 2010, 22, 104-114. [CrossRef]

4. Yamaguchi, K. Forming Troubles Such as Mold Pollution and Preventable Techniques. Soc. Rubber Sci. Technol. Jpn. 2017, 90, 47-53. [CrossRef]

5. Oohira, K. Characteristics and Applications of DLC films. NTN Tech. Rev. 2009, 77, 90-95.

6. Roy, R.K.; Ahmed, S.F.; Yi, J.W.; Moon, M.-W.; Lee, K.-R.; Jun, Y. Improvement of adhesion of DLC coating on nitinol substrate by hybrid ion beam deposition technique. Vacuum 2009, 83, 1179-1183. [CrossRef]

7. Ohtake, N.; Hiratsuka, M.; Kanda, K.; Akasaka, H.; Tsujioka, M.; Hirakuri, K.; Hirata, A.; Ohana, T.; Inaba, H.; Kano, M.; et al. Properties and Classification of Diamond-Like Carbon Films. Materials 2021, 14, 315. [CrossRef] [PubMed]

8. Marciano, F.; Bonetti, L.; Da-Silva, N.; Corat, E.J.; Trava-Airoldi, V. Wettability and antibacterial activity of modified diamond-like carbon films. Appl. Surf. Sci. 2009, 255, 8377-8382. [CrossRef]

9. Marciano, F.; Bonetti, L.; Mangolin, J.; Da-Silva, N.; Corat, E.J.; Trava-Airoldi, V. Investigation into the antibacterial property and bacterial adhesion of diamond-like carbon films. Vacuum 2011, 85, 662-666. [CrossRef]

10. Lettington, A.H. Applications of diamond-like carbon thin films. Carbon 1998, 36, 555-560. [CrossRef]

11. Murata, S.; Ito, S.; Mizuno, J.; Hirakuri, K.; Sakamoto, H.; Masuko, S.; Sato, K.; Fukata, N.; Shizuku, F.; Shoji, S. Biochip applications of DLC films on a resin material. Phys. Status Solidi C 2012, 9, 1439-1442. [CrossRef]

12. Robertson, J. Properties of diamond-like carbon. Surf. Coat. Technol. 1992, 50, 185-203. [CrossRef]

13. Robertson, J. Diamond-like amorphous carbon. Mater. Sci. Eng. R Rep. 2002, 37, 129-281. [CrossRef]

14. Irmer, G.; Dorner-Reisel, A. Micro-Raman Studies on DLC coatings. Adv. Eng. Mater. 2005, 7, 694-705. [CrossRef]

15. Tuinstra, F.; Koenig, J.L. Raman Spectrum of Graphite. J. Chem. Phys. 1970, 53, 1126-1130. [CrossRef]

16. Ferrari, A.C. Raman spectroscopy of graphene and graphite: Disorder, electron-phonon coupling, doping and nonadiabatic effects. Solid State Commun. 2007, 143, 47-57. [CrossRef]

17. Iwamoto, Y.; Takenami, K.; Takamura, R.; Inoue, M.; Hirara, Y.; Akasaka, H.; Ohtake, N. Preparation of DLC films on inner surfaces of metal tubes by nanopulse plasma CVD. Surf. Coat. Technol. 2019, 380, 125062. [CrossRef] 
18. Bellido-González, V.; Hampshire, J.; Jones, A.; Allen, T.; Witts, J.; Teer, D.; Pierret, B. Advances in the analysis and characterization of DLC coatings. Surf. Coat. Technol. 1998, 98, 1272-1279. [CrossRef]

19. Petereit, B.; Siemroth, P.; Schneider, H.-H.; Hilgers, H. High current filtered arc deposition for ultra thin carbon overcoats on magnetic hard disks and read-write heads. Surf. Coat. Technol. 2003, 174-175, 648-650. [CrossRef]

20. Terrones, M.; Mendez, A.R.B.; Campos-Delgado, J.; López-Urías, F.; Vega-Cantú, Y.I.; Rodríguez-Macías, F.J.; Elías, A.L.; MuñozSandoval, E.; Cano-Márquez, A.G.; Charlier, J.-C. Graphene and graphite nanoribbons: Morphology, properties, synthesis, defects and applications. Nano Today 2010, 5, 351-372. [CrossRef]

21. Savage, R.H. Graphite Lubrication. J. Appl. Phys. 1948, 19, 1-10. [CrossRef]

22. Novoselov, K.S.; Geim, A.K.; Morozov, S.V.; Jiang, D.; Zhang, Y.; Dubonos, S.V.; Grigorieva, I.V.; Firsov, A.A. Electric field effect in atomically thin carbon films. Science 2004, 306, 666-669. [CrossRef] [PubMed]

23. Terasawa, T.-O.; Saiki, K. Growth of graphene on Cu by plasma enhanced chemical vapor deposition. Carbon 2012, 50, 869-874. [CrossRef]

24. Tsuchiya, F.; Suzuki, H. Improvement of the Mold Releasing Properties by DLC Surface Modification for the Injection Processing. Hyomen Gijutsu J. Surf. Finish. Soc. Jpn. 2007, 58, 130-135. [CrossRef]

25. Wang, Y.; Jiang, B.; Zhou, M.; Chen, J.; Weng, C. Influence of Diamond-Like Carbon Coating on the Channel Deformation of Injection-Molded Microfluidic Chips during the Demolding Process. Polymers 2020, 12, 2914. [CrossRef]

26. Wang, D.-Y.; Weng, K.-W.; Chang, C.-L.; Ho, W.-Y. Synthesis of Cr3C2 coatings for tribological applications. Surf. Coat. Technol. 1999, 120-121, 622-628. [CrossRef]

27. Kawaguchi, Y.; Nonaka, F.; Sanada, Y. Fluorinated materials for UV nanoimprint lithography. Microelectron. Eng. 2007, 84, 973-976. [CrossRef]

28. Ferrari, A.C.; Robertson, J. Interpretation of Raman spectra of disordered and amorphous carbon. Phys. Rev. B 2000, 61, 14095-14107. [CrossRef]

29. Campion, A.; Kambhampati, P. Surface-enhanced Raman scattering. Chem. Soc. Rev. 1998, 27, 241-250. [CrossRef]

30. Schneider, C.A.; Rasband, W.S.; Eliceiri, K.W. NIH Image to ImageJ: 25 years of image analysis. Nat. Methods 2012, 9, 671-675. [CrossRef]

31. Boubiche, N.; El Hamouchi, J.; Hulik, J.; Abdesslam, M.; Speisser, C.; Djeffal, F.; Le Normand, F. Kinetics of graphitization of thin diamond-like carbon (DLC) films catalyzed by transition metal. Diam. Relat. Mater. 2019, 91, 190-198. [CrossRef]

32. Ilie, A.; Ferrari, A.C.; Yagi, T.; Rodil, S.E.; Robertson, J.; Barborini, E.; Milani, P. Role of sp2 phase in field emission from nanostructured carbons. J. Appl. Phys. 2001, 90, 2024-2032. [CrossRef]

33. Argile, C.; Rhead, G. Adsorbed layer and thin film growth modes monitored by Auger electron spectroscopy. Surf. Sci. Rep. 1989, 10, 277-356. [CrossRef]

34. Hang, Z.Y.; Thompson, C.V. Grain growth and complex stress evolution during Volmer-Weber growth of polycrystalline thin films. Acta Mater. 2014, 67, 189-198.

35. Ohring, M. Materials Science of Thin Films; Elsevier: Amsterdam, The Netherlands, 2001.

36. Petrov, I.; Barna, P.B.; Hultman, L.; Greene, J.E. Microstructural evolution during film growth. J. Vac. Sci. Technol. A 2003, 21, S117-S128. [CrossRef]

37. Thompson, C.V. Structure Evolution During Processing of Polycrystalline Films. Annu. Rev. Mater. Res. 2000, 30, 159-190. [CrossRef]

38. A Friesen, C.; Seel, S.C.; Thompson, C.V. Reversible stress changes at all stages of Volmer-Weber film growth. J. Appl. Phys. 2004, 95, 1011-1020. [CrossRef]

39. Zhou, B.; Rogachev, A.; Liu, Z.; Jiang, X.; Shen, R.; Rudenkov, A. Structure and mechanical properties of diamond-like carbon films with copper functional layer by cathode arc evaporation. Surf. Coat. Technol. 2012, 208, 101-108. [CrossRef]

40. Dwivedi, N.; Kumar, S.; Dayal, S.; Rauthan, C.M.; Panwar, O.S. Studies of nanostructured copper/hydrogenated amorphous carbon multilayer films. J. Alloy. Compd. 2011, 509, 1285-1293. [CrossRef]

41. Lespade, P.; Al-Jishi, R.; Dresselhaus, M. Model for Raman scattering from incompletely graphitized carbons. Carbon 1982, 20, 427-431. [CrossRef]

42. Lu, Y.; Huang, G.; Xi, L. Tribological and mechanical properties of the multi-layer DLC film on the soft copper substrate. Diam. Relat. Mater. 2019, 94, 21-27. [CrossRef] 